\title{
Teaching and learning evidence-based medicine: cross-sectional survey investigating knowledge and attitudes of teachers and learners in primary and secondary care
}

A NIROSHAN SIRIWARDENA, JOHN SANDARS, ISLAY GEMMELL and ALY RASHID

\section{WHAT IS ALREADY KNOWN IN THIS AREA}

- There is little evidence on the relationship between attitudes and knowledge in relation to evidence-based medicine (EBM) in family doctors, consultants and doctors in training.

\section{WHAT THIS WORK ADDS}

- This study showed that, although general practitioners and general practitioner trainers were significantly less positive in attitude to EBM compared to GP registrars, junior hospital doctors and consultant respondents, they had significantly higher knowledge scores.

- This study demonstrated that the attitude (PEP) score and knowledge questionnaire (MANSEBMQ) have high reliability but require further research to demonstrate validity.

\section{SUGGESTIONS FOR FURTHER RESEARCH}

- There remain opportunities for refinement of the MANSEBMQ, validation against existing tools and further application in a larger study, including assessment of EBM knowledge and skills, before and after an educational process, involving students in clinically relevant and integrated EBM learning.

Keywords: attitudes, evidence-based practice, general practice registrars, general practitioners, hospital doctors, primary care, secondary care

\section{SUMMARY}

Evidence-based medicine (EBM) is an important component of quality healthcare and a key part of the curriculum for doctors in training. There have been no previous studies comparing attitudes and knowledge of doctors in primary and secondary care towards EBM practice and teaching and this study sets out to investi- gate this area. We asked participants, a stratified sample of general practitioners, hospital consultants, GP registrars and junior hospital doctors in Leicester, Northamptonshire and Rutland, UK, to complete a self-administered survey questionnaire and written knowledge test which provided 'positive to evidencebased practice' (PEP) attitude scores and Manchester Short EBM Questionnaire 
(MANSEBMQ) knowledge scores of participants.

The response rate was low which may have led to volunteer bias but there were sufficient responses to explore attitude scores and knowledge scores. Attitude (PEP) scores were highest in hospital consultants, intermediate in doctors in training and lowest in general practitioner (GP) respondents (mean score 71.7 vs 70.5 vs 67.2; $P=0.006$ ). PEP scores were also highest in respondents with higher degrees (MD, PhD, MSc), intermediate in those with higher professional qualifications (MRCP, FRCS, MRCGP or equivalent) and lowest in those with none of these (mean score 72.9 vs 70.6 vs $67.2 ; P=$ 0.005). PEP scores were significantly higher $(P=0.002)$ in respondents who taught EBM (mean score $71.7,95 \%$ CI 70.3 to $73.2, n=109$, missing $=5$ ) compared with those who did not (mean score 68.6, 95\% CI 67.3 to $69.9, n=105$, missing $=12$ ) and in respondents with research experience $(P<0.001)$, research training $(P<$ $0.001)$ and training in $\operatorname{EBM}(P=0.001)$. There was a positive correlation between PEP score and MANSEBMQ score $(P=$ 0.013). In contrast, and paradoxically opposite to the pattern of attitudes, knowledge scores were highest in GPs, intermediate in junior hospital doctors and lowest in consultant respondents (mean score 63.5 vs 61.9 vs $54.5, P=0.005)$.

Although GPs and GP trainers were significantly less positive in attitude to EBM compared to GP registrars, junior hospital doctors and consultant respondents, they had significantly higher knowledge scores. This study demonstrated that the attitude (PEP) score and knowledge questionnaire (MANSEBMQ) have good reliability but require further research to demonstrate validity.

\section{INTRODUCTION}

Barriers to practising EBM in primary and secondary care are due to negative atti- tudes, poor knowledge, ${ }^{1}$ deficient skills and organisational issues, such as lack of time. ${ }^{2}$ Patient resistance or rejection of evidence $^{3}$ and issues such as applicability, interpretation, validity, or contradictory evidence $^{4}$ are also important barriers. Lack of evidence that critical appraisal training improves decision making or patient outcomes $^{5}$ may be partly to blame for negative attitudes. However, teaching EBM involves accessing, appraising and applying evidence rather than solely critical appraisal. $^{6-8}$

Although many doctors are positive towards the notion of practising EBM and despite evidence that teaching can increase knowledge and skills in EBM, ${ }^{9}$ few have attended formal training in EBM because of negative attitudes, lack of confidence (particularly in statistics), time or funding. $^{10}$

Medical educators, both in primary (GP trainers and course organisers) and secondary care (hospital consultants), are expected to be able to understand and teach EBM. EBM is also a key part of the curriculum for today's junior doctors, both to be able to practise high-quality care (of which EBM is a component $)^{11}$ and to complete various professional examinations where EBM forms a significant component.

There has been limited research into EBM teaching and little is known about the knowledge and attitudes of medical teachers and learners in relation to EBM. This study sets out to investigate this area in further detail, building on findings from a recent qualitative study. ${ }^{12}$ It seeks to explore attitudes and knowledge of doctors in relation to EBM in order to address the learning needs of medical educators to improve the teaching of EBM.

\section{METHOD}

\section{Study design}

A self-administered postal questionnaire survey was used to identify knowledge, 
attitudes and sociodemographic characteristics from a sample of doctors in Leicestershire, Northamptonshire and Rutland (UK). Subjects were a stratified random sample of doctors including GP trainers, GP registrars, hospital consultants and junior hospital doctors in this region. Registers of doctors were accessed via the postgraduate deanery. A single reminder was sent after four weeks if there was no response to the initial questionnaire. Participants were offered feedback on their score in the EBM questionnaire. Knowledge was assessed using an instrument, the Manchester Short EBM Questionnaire (MANSEBMQ), developed at Manchester University. This questionnaire had undergone initial validation using a sample of 50 GPs. Item statistics, reliability and face validity had been shown to be satisfactory for the pilot questionnaire (unpublished data). Perceptions, attitudes and beliefs were measured using a novel instrument, the 'positive to evidence-based practice' (PEP) score, which was developed and validated as part of this study. The null hypothesis was that there would be no difference in attitudes to EBM and knowledge of EBM (using MANSEBMQ) scores between the experts and the novices.

\section{Questionnaire domains}

The MANSEBMQ tested knowledge in the three areas of accessing, appraising and applying evidence. Attitudes to EBM were measured using the PEP score, which was derived from the sum (with positive questions recoded) of responses using a Likert scale to a 'balanced' (equal numbers of positive and negative items) questionnaire. The domains were produced following a review of the literature and a qualitative study. ${ }^{12}$ These included overall attitudes to EBM, perceived range and quality of evidence, threats to professionalism and litigation from EBM, whether EBM should be taught by practising clinicians or experts, and the effect on quality of care of EBM.

\section{Data analysis}

Questionnaire responses were entered onto a spreadsheet (Excel) and imported to statistical analysis software (SPSS). The relationship between attitudes, knowledge and sociodemographic variables were analysed using chi-square and Mann-Whitney U tests for non-parametric data and ANOVA for parametric data. Reliability was determined for both questionnaires using Cronbach's alpha. Knowledge questions were analysed with classic measurement theory using facility (percentage of correct responses) and item discrimination (point biserial correlation) index. Construct validity of the instrument was tested by exploring relationships between attitudinal and knowledge scores for experts and novices in EBM. Respondents who were experts in EBM (e.g. teachers of EBM and those with research degrees) were hypothesised to be more likely to have better knowledge and attitudinal scores than novices.

Sample size for the primary outcome variable (MANSEBMQ score) was determined assuming $80 \%$ power and $5 \%$ two-tailed significance level. To detect a difference in scores of $10 \%$ (based on estimates from pilot data) between experts (average score 65\%) and novices (average score 55\%), it was determined that 376 respondents would be required in each group, giving a total of 752 . Assuming a $60 \%$ response rate to the questionnaire it was estimated that we would need to contact 1253 potential respondents, 627 in each group. Assuming that trainers and consultants were experts and GP registrars and junior doctors novices, we aimed to recruit $700 \mathrm{GP}$ trainers and consultants and 700 GP registrars and junior hospital doctors to each group. 


\section{RESULTS}

\section{Response rate}

The response rate to the survey was poor. Overall, 236 of $1400(16.9 \%)$ invitees responded. However, the purpose of the study was to compare teachers and learners of EBM and almost half the respondents were medical teachers (Table 1), enabling relevant comparisons to be made between learners and teachers who responded to the questionnaire. The most common reason for non-response was lack of time to complete the questionnaire and the reluctance to complete a knowledge test in a busy clinical schedule.

Table 1 Demographic characteristics of respondents ( $n=236$ )

\begin{tabular}{|c|c|c|}
\hline Characteristics & $n(\%)$ & \\
\hline \multicolumn{3}{|l|}{ Gender } \\
\hline Male & 153 & $(64.8)$ \\
\hline Female & 82 & $(34.7)$ \\
\hline \multicolumn{3}{|l|}{ Age } \\
\hline$<25$ & 3 & $(1.3)$ \\
\hline $25-34$ & 93 & $(39.4)$ \\
\hline 35-44 & 68 & $(28.8)$ \\
\hline $45-54$ & 48 & (20.3) \\
\hline $55-64$ & 23 & $(9.7)$ \\
\hline 65 or over & 1 & $(0.4)$ \\
\hline \multicolumn{3}{|l|}{ Designation } \\
\hline Consultant & 87 & (36.9) \\
\hline GP, GP trainer or tutor & 40 & $(16.9)$ \\
\hline Specialist registrar & 63 & $(26.7)$ \\
\hline $\mathrm{SHO}$ & 22 & $(9.3)$ \\
\hline GP registrar & 15 & $(16.4)$ \\
\hline \multicolumn{3}{|l|}{ Postgraduate qualification } \\
\hline MD, PhD or MSc & 28 & $(11.9)$ \\
\hline Membership or fellowship & 165 & $(69.9)$ \\
\hline Other & 43 & $(18.2)$ \\
\hline \multicolumn{3}{|l|}{ Teaching } \\
\hline Teaching role & 115 & $(48.7)$ \\
\hline Role teaching EBM & 114 & $(48.3)$ \\
\hline
\end{tabular}

\section{Attitudes to EBM}

Respondents were positive overall in their attitudes to EBM as judged by responses to 24 attitude statements on EBM on a five-point Likert scale (Table 2).

These items were combined (by recoding positive statements) to form an attitude score, the PEP score. This had a high degree of internal consistency - reliability coefficient (Cronbach's alpha) 0.81.

PEP scores were highest in hospital consultants, intermediate in doctors in training (including specialist registrars, GP registrars and senior house officers) and lowest in GPs, including GP trainers (mean score 71.7 vs 70.5 vs $67.2 ; P=$ 0.006 , see Table 3). However, within this specialist registrars $(71.8 ; 95 \%$ CI 70.1 to 73.5) and consultants $(71.7 ; 69.9$ to 73.5$)$ had the highest PEP scores and GPs (66.3; 63.5 to 69.1$)$, GP trainers $(67.9 ; 64.2$ to $71.5)$ and GP registrars $(66.7 ; 62.4$ to 70.9$)$ the lowest.

PEP scores were also highest in respondents with higher degrees (MD, PhD, $\mathrm{MSc}$ ), intermediate in those with higher professional qualifications (MRCP, FRCS, MRCGP or equivalent) and lowest in those with none of these (mean score 72.9 vs 70.6 vs $67.2 ; P=0.005$, Table 3 ).

PEP scores were significantly higher $(P$ $=0.002)$ in respondents who taught EBM (mean score $71.7,95 \%$ CI 70.3 to $73.2, n$ $=109$, missing $=5$ ) compared with those who did not (mean score $68.6,95 \%$ CI 67.3 to $69.9, n=105$, missing $=12$ ).

PEP scores were also significantly higher in respondents with research experience $(P<0.001)$, research training $(P<0.001)$ and training in $\operatorname{EBM}(P=0.001)$. Respondents who agreed or strongly agreed with the statement, 'I am confident of my ability to teach EBM' had significantly higher PEP scores than those who disagreed or strongly disagreed with this statement $(P<0.001)$. Doctors who stated that they accessed published research more frequently also had higher PEP scores $(P<$ $0.001)$. 
Table 2 Responses of 236 doctors to statements on attitudes to evidence-based medicine

$\%$ of doctors responding

Mean

score

(Strongly) Not (Strongly) Missing

Agree sure Disagree

General

Evidence-based medicine (EBM) is a welcome development $(+)$

Lack of time prevents me from practising EBM (-)

Adoption of EBP is an unnecessary demand on overloaded professionals (-)

I have confidence in my own EBM skills (+)

I am driven to using EBM because of the threat

of litigation (-)

I feel EBM is an integral part of good professional practice $(+)$

$\begin{array}{rrrrr}91.1 & 5.9 & 1.7 & 1 & 4.20 \\ 33.5 & 19.9 & 45.4 & 1 & 3.11 \\ 3.4 & 12.3 & 82.6 & 2 & 4.00 \\ 44.0 & 41.1 & 13.5 & 1 & 3.29 \\ 25.8 & 17.4 & 55.1 & 1 & 3.35 \\ 93.6 & 4.7 & 0.4 & 1 & 4.22\end{array}$

\section{Accessing evidence}

I have access to copies of published research

relating to my clinical practice $(+)$

I do not have the skills to access published research (-)

I am confident to access published research (+)

I do not have the time to look for published research (-)

86.8

$\begin{array}{llll}5.1 & 6.4 & 1 & 4.07\end{array}$

8.9

75.0

7.6

81.8

$16.1 \quad 7.6$

4.00

39.8

19.5

39.5

3.87

2.99

\section{Appraising evidence}

I have skills to appraise evidence (+)

67.2

I am confident to appraise published research (-)

Appraisal of evidence should be conducted by

credible experts (-)

All I am interested in is the summary of the evidence (-)

I do not have time to appraise published research (-)

41.1

43.6

$\begin{array}{llll}16.5 & 14.0 & 1 & 3.64 \\ & & & \\ 26.3 & 16.5 & 1 & 3.48 \\ 14.4 & 21.2 & 1 & 2.49 \\ & & & \\ 19.9 & 37.3 & 2 & 2.94 \\ 16.9 & 37.7 & 1 & 2.86\end{array}$

Applying evidence

EBM improves patient care (+)

78.0

18.6

2.1

3.98

There is insufficient evidence on which to base my practice (-)

It is difficult to apply EBM to individual patients (-)

EBM is easily applied to the population of patients

I look after (+)

EBM conflicts with the needs of my patients (-)

28.0

2

47.0

3.18

36.4

(1).

35.2

$16.1 \quad 44.5$

$44.5 \quad 3$

3.06

$\begin{array}{llll}32.6 & 30.0 & 2 & 3.05\end{array}$

EBM fits with my personal experience of what works $(+)$

EBM complements my normal practice $(+)$

EBM is a threat to professionalism (-)

I enjoy positive feedback from patients in applying 
Table 3 Positive to evidence-based practice (PEP) scores comparing consultants, GPs and doctors in training and those with higher qualifications

$\begin{array}{ll}\text { PEP score } 95 \% \mathrm{Cl} & \begin{array}{l}\text { Missing ANOVA } \\ \text { values }\end{array}\end{array}$

\section{Designation \\ Consultants $(n=79)$ \\ GPs or GP trainers $(n=40)$ \\ GP registrars or junior hospital doctors \\ $(n=93)$ \\ Qualification \\ MD, PhD or MSc $(n=26)$ \\ Manchester Short EBM Questionnaire (MANSEBMQ) scores}

71.7

67.2

70.5

72.9

70.6

67.2
69.9 to 73.5

65.0 to 69.3

69.1 to 72.0
8

0

$$
P=0.006
$$

MANSEBMQ scores were expressed as a percentage. The questionnaire had a high reliability, with a reliability coefficient for internal consistency (Cronbach's alpha) of 0.93. Fifty-six out of $74(75.7 \%)$ questions had a facility (proportion of correct answers) between 0.2 and 0.8 , suggesting that the majority of questions were of appropriate difficulty. Fifty out of 73 questions $(68.5 \%)$ had discrimination (or point-biserial correlation) of 0.2 or greater, indicating those items which were good at discriminating those who performed well in the test overall with those who did not. Table 4 shows item facility, discrimination, correlation between individual items and total score and reliability if individual items are excluded.

There was a positive correlation between PEP score and MANSEBMQ score, correlation coefficient (Spearman's rho) 0.17, $P=0.013$ (two-tailed). Manchester scores were highest in GPs and GP trainers, intermediate in hospital doctors and lowest in consultant respondents (mean score 63.5 vs 61.9 vs $54.5, P=0.005$ ). Paradoxically this was opposite to the pattern of attitudes.

There was no significant difference in Manchester scores comparing those who had higher degrees, professional college membership or fellowship or neither of these (mean score 58.5 vs 58.8 vs 61.8 ); nor comparing those who had a teaching role with those who did not (mean score 58.0 vs 60.7); nor comparing those who taught EBM with those who did not (mean score 59.3 vs 59.5 ); neither was there a positive relationship between scores and EBM training. However, these negative findings occurred in the context of a low response rate.

Respondents who had training in EBM were significantly more likely to score in the top quartile of Manchester scores (chi square $=11.6, \mathrm{df}=4, P=0.021)$. However, there was no difference in mean scores of those who had trained in EBM compared with those who had not.

\section{DISCUSSION}

\section{Principal findings}

Both parts of the questionnaire, relating to attitudes (PEP score) and knowledge (MANSEBMQ) were reliable. There were more positive attitudes to EBM in participants who were hospital consultants, those with higher degrees, teachers and teachers of EBM, and those with research experience, research training or training in EBM. Positive attitudes to EBM correlated sig- 
Table 4 Table item statistics for Manchester EBM questionnaire

\begin{tabular}{|c|c|c|c|c|}
\hline & Facility & Discrimination & $\begin{array}{l}\text { Corrected item - } \\
\text { total correlation }\end{array}$ & $\begin{array}{l}\text { Cronbach's alpha } \\
\text { if item deleted }\end{array}$ \\
\hline MQ1 & 0.83 & 0.48 & 0.659 & 0.927 \\
\hline MQ2 & 0.46 & 0.30 & 0.293 & 0.929 \\
\hline MQ3 & 0.56 & 0.41 & 0.400 & 0.928 \\
\hline MQ4 & 0.61 & 0.57 & 0.519 & 0.927 \\
\hline MQ5 & 0.36 & 0.13 & 0.157 & 0.930 \\
\hline MQ6 & 0.58 & 0.34 & 0.321 & 0.929 \\
\hline MQ7 & 0.59 & 0.57 & 0.503 & 0.927 \\
\hline MQ8 & 0.69 & 0.61 & 0.578 & 0.927 \\
\hline MQ9 & 0.58 & 0.53 & 0.519 & 0.927 \\
\hline MQ10 & 0.18 & 0.14 & 0.170 & 0.929 \\
\hline MQ11a & 0.77 & -0.01 & -0.155 & 0.931 \\
\hline MQ11b & 0.54 & 0.72 & 0.583 & 0.927 \\
\hline MQ11c & 0.88 & 0.13 & 0.015 & 0.930 \\
\hline MQ12a & 0.62 & 0.77 & 0.709 & 0.926 \\
\hline MQ12b & 0.56 & 0.84 & 0.704 & 0.926 \\
\hline MQ12C & 0.55 & 0.63 & 0.571 & 0.927 \\
\hline MQ13a & 0.64 & 0.62 & 0.602 & 0.927 \\
\hline MQ13b & 0.82 & 0.03 & -0.066 & 0.930 \\
\hline MQ13c & 0.86 & 0.09 & -0.065 & 0.930 \\
\hline MQ14a & 0.44 & -0.30 & -0.411 & 0.933 \\
\hline MQ14b & 0.55 & 0.47 & 0.436 & 0.928 \\
\hline MQ14C & 0.36 & 0.47 & 0.394 & 0.928 \\
\hline MQ15a & 0.32 & 0.51 & 0.433 & 0.928 \\
\hline MQ15b & 0.81 & 0.05 & -0.130 & 0.931 \\
\hline MQ15c & 0.53 & 0.67 & 0.559 & 0.927 \\
\hline MQ16a & 0.90 & 0.04 & -0.075 & 0.930 \\
\hline MQ16b & 0.67 & 0.71 & 0.706 & 0.926 \\
\hline MQ16c & 0.90 & 0.03 & -0.098 & 0.930 \\
\hline MQ17a & 0.77 & 0.67 & 0.790 & 0.926 \\
\hline MQ17b & 0.53 & 0.72 & 0.602 & 0.927 \\
\hline MQ17c & 0.94 & 0.09 & 0.036 & 0.929 \\
\hline MQ18a & 0.66 & 0.75 & 0.701 & 0.926 \\
\hline MQ18b & 0.70 & -0.13 & -0.251 & 0.932 \\
\hline MQ18c & 0.80 & -0.03 & -0.161 & 0.931 \\
\hline MQ19a & 0.61 & 0.77 & 0.652 & 0.927 \\
\hline MQ19b & 0.28 & 0.30 & 0.285 & 0.929 \\
\hline MQ19c & 0.94 & 0.13 & 0.052 & 0.929 \\
\hline MQ20 & 0.56 & 0.63 & 0.556 & 0.927 \\
\hline MQ20b & 0.80 & -0.01 & -0.177 & 0.931 \\
\hline MQ20c & 0.21 & 0.32 & 0.337 & 0.928 \\
\hline MQ21a & 0.62 & 0.80 & 0.700 & 0.926 \\
\hline MQ21b & 0.80 & -0.06 & -0.199 & 0.931 \\
\hline MQ21c & 0.74 & -0.01 & -0.193 & 0.931 \\
\hline MQ22a & 0.60 & 0.62 & 0.556 & 0.927 \\
\hline MQ22b & 0.69 & 0.73 & 0.728 & 0.926 \\
\hline MQ22C & 0.64 & 0.72 & 0.667 & 0.926 \\
\hline MQ23a & 0.62 & -0.23 & -0.308 & 0.932 \\
\hline MQ23b & 0.19 & 0.35 & 0.346 & 0.928 \\
\hline MQ23c & 0.25 & 0.34 & 0.326 & 0.929 \\
\hline MQ24a & 0.66 & 0.84 & 0.785 & 0.926 \\
\hline MQ24b & 0.55 & 0.78 & 0.673 & 0.926 \\
\hline MQ24c & 0.45 & 0.80 & 0.643 & 0.927 \\
\hline
\end{tabular}


Table 4 Continued

\begin{tabular}{llccc}
\hline & Facility & Discrimination & $\begin{array}{c}\text { Corrected item }- \\
\text { total correlation }\end{array}$ & $\begin{array}{l}\text { Cronbach's alpha } \\
\text { if item deleted }\end{array}$ \\
\hline MQ24d & 0.53 & 0.80 & 0.662 & 0.926 \\
MQ24e & 0.51 & 0.77 & 0.632 & 0.927 \\
MQ25a & 0.69 & -0.35 & -0.378 & 0.933 \\
MQ25b & 0.61 & 0.86 & -0.136 & 0.926 \\
MQ25c & 0.87 & -0.03 & 0.623 & 0.930 \\
MQ26a & 0.52 & 0.77 & 0.197 & 0.927 \\
MQ26b & 0.13 & 0.16 & 0.732 & 0.929 \\
MQ26c & 0.57 & 0.89 & 0.530 & 0.926 \\
MQ27a & 0.33 & 0.65 & 0.455 & 0.927 \\
MQ27b & 0.34 & 0.51 & 0.569 & 0.928 \\
MQ27c & 0.42 & 0.71 & 0.596 & 0.927 \\
MQ27d & 0.44 & 0.75 & 0.610 & 0.927 \\
MQ28a & 0.48 & 0.76 & 0.313 & 0.927 \\
MQ28b & 0.20 & 0.33 & 0.507 & 0.929 \\
MQ28c & 0.39 & 0.65 & 0.616 & 0.927 \\
MQ29a & 0.53 & 0.75 & 0.512 & 0.927 \\
MQ29b & 0.41 & 0.65 & 0.681 & 0.927 \\
MQ29c & 0.58 & 0.77 & -0.104 & 0.926 \\
MQ30a & 0.83 & 0.04 & 0.433 & 0.931 \\
MQ30b & 0.30 & 0.53 & -0.038 & 0.928 \\
MQ30c & 0.88 & 0.10 & & 0.930 \\
\hline
\end{tabular}

Facility = proportion answering correctly; Discrimination = proportion answering correctly in top tertile minus proportion answering correctly in bottom tertile divided by half number in both; ideally 0.2 or greater; Corrected item - total correlation $=$ correlation between this item and other items in the test; Cronbach's alpha if item deleted $=$ effect on reliability if item removed from test

nificantly with performance in the Manchester short EBM test. Those who had training in EBM were significantly more likely to score in the top quartile of Manchester scores. These findings supported the construct validity of the test. Although Manchester scores were not significantly higher in any of the groups who were more positive in their attitudes, those who had undergone training in EBM were more likely to score in the top quartile of MANSEBMQ scores. The lack of other significant associations may have been because the study, due to a low response rate, was underpowered to detect significant differences between these groups.

\section{Strengths and weaknesses}

Strengths of the study included wide sam- pling from doctors in primary and secondary care including both teachers and students of EBM across a wide geographical area. The MANSEBMQ also had good facility scores and good discrimination for the majority of items. The main weakness of the study was the low response rate, which is not unexpected in a study of this kind requiring participants to undergo an assessment. This may well have led to volunteer bias, with lower response rates in those less confident (but not necessarily less informed) on the subject of EBM. There were likely to be others who started the questionnaire but then gave up, becoming non-responders. The study was wholly based on analysis of questionnaires and limitation of resources prevented triangulation with qualitative data. Despite these shortcomings useful data were nevertheless obtained. 
Table 5 Manchester short EBM questionnaire (MANSEBMQ) scores comparing consultants GPs and doctors in training and those with higher qualifications

$\begin{array}{ll}\text { MANSEBMQ } 95 \% \mathrm{Cl} & \begin{array}{l}\text { Missing ANOVA } \\ \text { values }\end{array}\end{array}$

Designation

Consultants $(n=83)$

GPs or GP trainers ( $n=39)$

GP registrars or junior hospital doctors $(n=97)$

\section{Qualification}

MD, PhD or MSc $(n=26)$

Royal College membership or fellowship $(n=160)$

Neither $(n=42)$
54.5

63.5

61.9

58.5

58.8

61.7

\section{3 to $58.8 \quad 4$}

57.8 to $69.3 \quad 1$

58.7 to $65.1 \quad 3$

$P=0.006$

3

51.5 to $65.5 \quad 1$

55.9 to $61.8 \quad 2$

57.2 to $66.3 \quad 5$

\section{Comparison with existing literature}

Because self-rating is only a weak indicator of knowledge and skills s.13 $^{1,13}$ the development of valid assessments of EBM knowledge and skills around the core competencies for evidence-based practice (EBP), which include formulating answerable questions, accessing, appraising, applying and evaluating the application of evidence, is of key importance. ${ }^{14}$ Existing tools, including the Fresno test ${ }^{15}$ and the Berlin questionnaire, ${ }^{9}$ have been validated by comparing scores between experts and students before and after an intervention but suffer from dependence on expert assessors to rate completed tests which requires time and resources.

Because the MANSEBMQ was short and constructed as a multiple-choice questionnaire it is easier to administer than other assessments whilst maintaining a high reliability. Unfortunately the study did not adequately demonstrate construct validity for MANSEBMQ comparing selfreported expertise, inferred from possession of higher qualifications, a selfreported or implied teaching role whether in EBM or teaching in general. Respondents trained in EBM were significantly more likely to score in the top quartile of Manchester scores, lending a degree of support to validity. Also, such question- naires may be distinct from the activity of practising EBM.

Previous studies have suggested that both GPs and hospital doctors lack knowledge and skills in relation to EBP. 2,16,17 O'Donnell also found that GPs felt less able to carry out appraisal of literature compared to nurses or public health practitioners ${ }^{17}$ despite having better access to these resources than community staff. ${ }^{18}$ The lack of confidence in family doctors is found in other studies. ${ }^{19}$ Higher academic qualifications were associated with greater use of the Cochrane Library in hospital doctors. ${ }^{16}$

It is difficult to explain the paradox that more positive attitudes in hospital consultant respondents were not associated with greater knowledge in this study. The result may have been due to low response and volunteer bias favouring GPs who had a greater interest and ability in EBM. Another possible explanation is that responding consultants possessed a selfimage that they employed an EBM approach that was not matched by knowledge. A number of studies have highlighted the particular difficulties that family doctors have with EBM. ${ }^{20,21}$ Other explanations are that the MANSEBMQ was less appropriate to a secondary care setting, too general practice orientated or not for 'experts'. Clearly these explanations are 
conjectural and there is little in the literature by way of explanation. Although there is some evidence that GP teachers are more effective in involving their students in the process of finding evidence, ${ }^{22}$ a study of decision making using clinical scenarios showed that both consultants and GP trainers could equally apply EBM risk measures such as predictive values or numbers needed to treat (NNT) and this 'real-life' use of the EBM knowledge is more typical of experts. ${ }^{23}$

\section{Opportunities for future research}

There remain opportunities for refinement of the MANSEBMQ, validation against existing tools and further application in a larger study including assessment of EBM knowledge and skills, before and after an educational process involving students in clinically relevant and integrated EBM learning. ${ }^{24,25}$

\section{Ethics}

This study was approved by Derbyshire Local Research Ethics Committee (reference number 04/Q2401/67) and the research management and governance organisations of participating doctors.

\section{Acknowledgements}

We would like to thank Leicestershire, Northamptonshire and Rutland Deanery for funding this study.

\section{Conflicts of interest}

None.

\section{References}

1 Khan KS, Awonuga AO, Dwarakanath LS and Taylor R (2001) Assessments in evidence- based medicine workshops: loose connection between perception of knowledge and its objective assessment. Medical Teacher 23: 92-4.

2 McColl A, Smith H, White P and Field $\mathbf{J}$ (1998) General practitioners' perceptions of the route to evidence based medicine: a questionnaire survey. BMJ 316: 361-5.

3 Freeman AC and Sweeney K (2001) Why general practitioners do not implement evidence: qualitative study. BMJ 323:1100-2.

4 Hammersley M (2001) Some Questions about Evidence-based Practice in Education. www.leeds.ac.uk/educol/documents/ 00001819.htm, pp.1-17. Paper presented at the symposium on 'Evidence-based practice in education' at the Annual Conference of the British Educational Research Association, University of Leeds, September 13-15, 2001.

5 Parkes J, Hyde C, Deeks J and Milne R (2001) Teaching critical appraisal skills in health care settings. Cochrane Database Systems Review CD001270.

6 Taylor R, Reeves B, Ewings P, Binns S, Keast J and Mears R (2000) A systematic review of the effectiveness of critical appraisal skills training for clinicians. Medical Education 34:120-5.

7 Norman GR and Shannon SI (1998) Effectiveness of instruction in critical appraisal (evidence-based medicine) skills: a critical appraisal. Canadian Medical Association Journal 158: $17 \overline{7-81 .}$

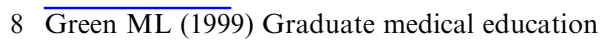
training in clinical epidemiology, critical appraisal, and evidence-based medicine: a critical review of curricula. Academic Medicine 74: 686-94.

9 Fritsche L, Greenhalgh T, Falck-Ytter Y, Neumayer HH and Kunz R (2002) Do short courses in evidence based medicine improve knowledge and skills? Validation of Berlin questionnaire and before and after study of courses in evidence based medicine. BMJ 325 : 1338-41.

10 Greenhalgh T and Douglas HR (1999) Experiences of general practitioners and practice nurses of training courses in evidence-based health care: a qualitative study. British Journal of General Practice 49: 536-40.

11 Department of Health (1998) A First Class Service: quality in the new NHS. Department of Health: London.

12 Siriwardena AN, Sandars J and Scott K (2004) Attitudes of GP trainers to teaching evidence 
based medicine. Education for Primary Care 15: 611-17.

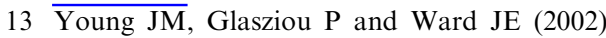
General practitioners' self ratings of skills in evidence based medicine: validation study. BMJ 324: 950-1.

14 Dawes M, Summerskill WS, Glasziou P et al (2005) Sicily statement on evidence-based practice. BMC Medical Education 5: 1.

15 Ramos KD, Schafer S and Tracz SM (2003) Validation of the Fresno test of competence in evidence based medicine. BMJ 326: 319-21.

16 Oliveri RS, Gluud C and Wille-Jorgensen PA (2004) Hospital doctors' self-rated skills in and use of evidence-based medicine - a questionnaire survey. Journal of Evaluation and Clinical Practice 10: 219-26.

17 O'Donnell CA (2004) Attitudes and knowledge of primary care professionals towards evidence-based practice: a postal survey. Journal of Evaluation and Clinical Practice 10: 197-205.

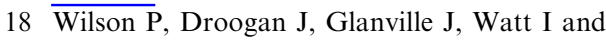
Hardman G (2001) Access to the evidence base from general practice: a survey of general practice staff in Northern and Yorkshire Region. Quality in Health Care 10: 83-9.

19 Beasley BW and Woolley DC (2002) Evidencebased medicine knowledge, attitudes and skills of community faculty. Journal of General Internal Medicine 17: 632-9.

20 Tracy CS, Dantas GC and Upshur REG (2005) Evidence-based medicine in primary care: qualitative study of family physicians. BMC Family Practice 4: 6.

21 Ely JW, Osheroff JA, Ebell MH et al (2002)
Obstacles to answering doctors' questions about patient care with evidence: qualitative study. BMJ 324:1-7.

22 Kljakovic M, Love T and Gilbert A (2004) Attitudes of teachers to evidence based medicine. Australian Family Physician 33: 376-8.

23 Heller RF, Sandars JE, Patterson L and McElduff P (2004) GPs' and physicians' interpretation of risks, benefits and diagnostic test results. Family Practice 21: 155-9.

24 Coomarasamy A and Khan KS (2004) What is the evidence that postgraduate teaching in evidence based medicine changes anything? A systematic review. BMJ 329: 1017.

25 Ghali WA, Saitz R, Eskew AH, Gupta M, Quan H and Hershmann WY (2003) Successful teaching in evidence-based medicine. Medical Education 34:18-22.

Correspondence to: Professor A Niroshan Siriwardena, School of Health and Social Care, University of Lincoln, Lincoln LN6 7BG, UK. Tel: +44 (0)784 365 8949; fax: + 44 (0)152 2870011 ; email: nsiriwardena@lincoln.ac.uk

A Niroshan Siriwardena, MMedSci PhD FRCGP, is Visiting Professor of Primary Care at the University of Lincoln. John Sandars, MBChB MSc FRCGP MRCP Cert Ed, is Senior Lecturer in Community Based Education at the University of Leeds. Islay Gemmell, MSc PhD, is a Research Fellow at the University of Manchester. Aly Rashid, MD FRCGP, is Associate Postgraduate Dean at the LNR Deanery, Leicester.

Accepted April 2006 


\section{APPENDIX 1: EXAMPLES FROM MANCHESTER SHORT EBM QUESTIONNAIRE}

\section{Examples of questions on accessing the evidence}

(Tick EITHER true or false)

You are interested in the risk of suicide in a patient with schizophrenia. The 'best' source of evidence is likely to be found in the Cochrane Library

$\square$ true $\square$ false

The main advantage of MEDLINE is that the studies included are assessed for methodological quality

$\square$ true $\quad \square$ false

\section{Examples of questions on appraising the evidence}

(Tick one OR MORE answers)

When trying to limit or narrow a search strategy, the following are useful strategies:

$\square$ use a truncation symbol $\left({ }^{\star}\right)$ to pick up variant endings

$\square$ use the Boolean operator AND

$\square$ include all publication types

Confounding factors can be reduced by:

$\square$ increasing the sample size

$\square$ randomisation

$\square$ stratification

\section{Examples of questions on applying the evidence}

Consider this hypothetical study of therapy for a disease...

\begin{tabular}{|lllc|}
\hline & Death from disease & $\begin{array}{l}\text { No death from } \\
\text { disease }\end{array}$ & Total \\
\hline $\begin{array}{l}\text { Experimental group } \\
\text { (therapy given) }\end{array}$ & 60 & 40 & 100 \\
$\begin{array}{l}\text { Control group } \\
\text { (no therapy given) }\end{array}$ & 80 & 20 & 100 \\
\hline
\end{tabular}


a. The event rate for death in the experimental group (EER) is 60\%<smiles>[AsH2]C1CCC1</smiles>

b. The absolute risk reduction (ARR) with therapy is $20 \%$

$\square$ true $\square$ false

(Tick one OR MORE answers)

The following apply to numbers needed to treat (NNT):

$\square$ the NNT does not depend on the prevalence of the disease

$\square$ an NNT of 10 means that ten people need to receive an intervention for one successful outcome

$\square$ the NNT is not related to the Absolute Risk Reduction 